[REVIEW ARTiCle]

\title{
TWO PERSPECTIVES ON THE ACQUISITION OF COMPLEX SENTENCES: INNATENESS AND LEARNING
}

\author{
KYOKO YAMAKOSHI \\ Senshu University*
}

The Acquisition of Complex Sentences, by Holger Diessel, Cambridge University Press, Cambridge, 2004, xvi+226pp.

Keywords: construction grammar, the usage-based model, the innateness hypothesis, infinitival complement constructions, relative clauses

\section{Introduction}

Diessel's The Acquisition of Complex Sentences examines the development of complex sentences in early child speech, based on vast observational data. The data consist of about 12,000 multiple clauses produced by five English-speaking children between the ages of $1 ; 8$ and 5;1, obtained from the CHILDES database (MacWhinney (1995)). This is probably the first study which has examined such a large amount of data in the acquisition of complex sentence constructions in English. In this sense, Diessel's detailed and thorough investigation contributes greatly to the study of the development of complex sentences. However, Diessel's analysis based on construction grammar and the usage-based model does not seem to be sufficient to undermine the innateness hypothesis proposed in the theory of generative grammar (Chomsky $(1965,1981,1986,1995,2000,2001,2004)$ ). In this review, some experimental studies based on the innateness hypothesis are introduced and compared with Diessel's analyses of the acquisition of com-

* I would like to thank Noriko Imanishi, Chizuko Inomata, Miwa Isobe, Eiko Mizuno, Tetsuya Sano, Hiroyuki Shimada and anonymous reviewers for their help and suggestions. I thank Bruce Thomas and David Anderson for proofreading. This work is supported by the grant from Senshu University for the research on children's language acquisition and the grant for the Open Research Center from the Ministry of Education, Culture, Sports, Science and Technology, and Senshu University. All remaining errors are my own. 
plex sentences.

Before going into the development of specific types of complex sentences, the difference between Diessel's theoretical framework and the innateness hypothesis is briefly examined in the next subsection.

\subsection{The Usage-Based Model and the Innateness Hypothesis}

Diessel's analyses crucially depend on the combination of construction grammar (Fillmore, Lay and O'Conner (1988), Fillmore and Kay (1993), Langacker (1987, 1991, 2000), Goldberg (1995), Croft (2001)) and the usage-based model (Bybee (1985, 2001), Langacker (1991), Barlow and Kemmer (2000), Elman, Bates, Johnson, Karmiloff-Smith, Parisi and Plunkett (1996).)

In construction grammar, constructions are the basic units of grammar. These constructions, which can be defined as combinations of forms and meaning (or function), exhibit both general grammatical properties and idiosyncratic features. Constructions vary along a scale of schematicity. A construction is schematic if it consists of abstract grammatical categories (e.g. NP, subject, etc.), and it is concrete if its components are filled by specific lexical items. Schematic constructions are also called 'constructional schemas.' A speaker's mental grammar includes highly abstract construction schemas, low-level formulas, and prefabricated chunks.

The usage-based model posits that linguistic structure emerges from language use (Langacker (1988, 2000); Bybee (1995); Elman et al. (1996)). One of the central assumptions is that the representation of linguistic elements correlates with frequency of occurrence. Linguistic expressions and grammatical patterns that occur with high frequency in language use are more deeply entrenched in mental grammar than those that are infrequent. Every time a speaker uses a linguistic expression (or grammatical pattern), it reinforces its mental representation, which in turn facilitates the activation of this expression in language use.

Linguistic knowledge is commonly represented in an activation network in the usage-based model. A network called a parallel distributed processing network (PDP network) (Elman et al. (1996)) consists of several layers of nodes and their connections. Both the nodes and their connections have 'weights' that change in the course of the simulation. The network in Figure 1 has three layers of nodes: the input nodes, the output nodes and the hidden nodes. 

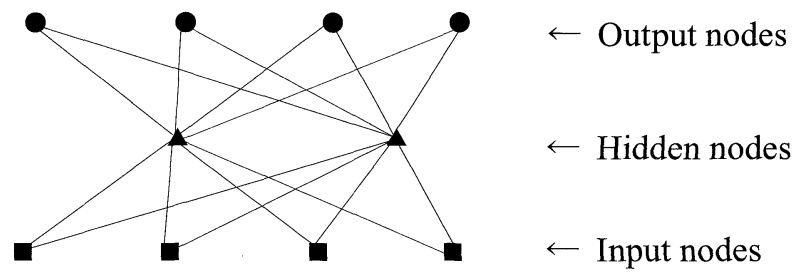

Figure 1. Distributed network (Diessel (2004: 27))

Constructions have an activation value called the "level of entrenchment' (Langacker (1987)). Linguistic expressions that are frequently used are more deeply entrenched (more highly activated) in the speaker's network of grammatical knowledge than linguistic expressions that are infrequent. There are two types of frequency: token frequency refers to the frequency of concrete expressions in the process of language use, and type frequency refers to the number of linguistic expressions that instantiate a constructional schema. A type can be defined as a construction that instantiates a particular constructional schema. While lexically specific constructions are highly entrenched in mental grammar if they occur with high token frequency, constructional schemas are argued to be highly entrenched if they occur with high type frequency. However, since the activation value of individual types is based on their number of tokens, token frequency is also indirectly involved in the entrenchment of a constructional schema.

In the usage-based approach, grammatical development is based on learning. It involves general psychological mechanisms such as habituation, entrenchment, and analogy. Habituation involves the routinization or automatization of complex verbal and nonverbal activities; entrenchment concerns the strength of mental representations; and analogy acts as a mechanism for the derivation of new knowledge. All three mechanisms are affected by the frequency of occurrence. Children will be able to build up representations of grammatical patterns only if they are frequently exposed to the relevant data. In other words, the frequency of occurrence plays an important role in learning. Since the usage-based model assumes that language acquisition is based on learning, it is expected that grammatical development is gradual. Learning requires repeated exposure to data over an extended period of time.

Contrary to the usage-based model, the innateness hypothesis in generative grammar assumes that children are endowed with innate linguistic knowledge, or 'universal grammar' (UG), which consists of universal principles and parameters (Chomsky (1981, 1986), Chomsky and Lasnik 
(1993)). Language acquisition is considered as independent of frequency in generative grammar. A parameter can be set to a specific value as soon as the child identifies the elements that can act as triggers. Assuming that most triggers are present in the input data, the theory of generative grammar predicts early and rapid acquisition.

Diessel tries to explain the development of four types of complex sentences by using the combination of construction grammar and the usagebased model. Other approaches based on the theory of generative grammar, however, will show different ways of explaining the development of complex sentences. In Section 2 and 3, we will focus on the development of infinitival complement constructions and relative clauses. After reviewing Diessel's analyses, other experimental studies which may contrast with Diessel's analyses will be introduced.

\section{Infinitival Complement Constructions}

\subsection{Diessel's Analysis}

Diessel (pp. 49, 62-76, 174-185) argues that the development of infinitival complement constructions can be seen as a process of clause expansion. Starting from structures that denote a single situation, children gradually learn the use of complex sentences in which a infinitival complement clause and a matrix clause express a specific relationship between two states of affairs.

The data Diessel examined are natural speech data of five English-speaking children, Adam, Sarah (Brown (1973)), Peter (Bloom (1973)), Nina (Suppes (1973)) and Naomi (Sachs (1983)), aged 1;8 to 5;1 (The CHILDES database; MacWhinney (1995)). Each child's age range, the numbers of utterances and multiple-clause utterances are given in the table below.

Table 1: General Overview of the Data (Diessel (2004: 9))

\begin{tabular}{|l|l|c|c|}
\hline Children & Age range & \# of utterances & $\begin{array}{c}\text { \# of multiple-clause } \\
\text { utterances }\end{array}$ \\
\hline Adam & $2 ; 3-4 ; 10$ & 46.498 & 4,389 \\
\hline Sarah & $2 ; 3-5 ; 1$ & 37,021 & 2,496 \\
\hline Nina & $1 ; 11-3 ; 4$ & 32,212 & 2,545 \\
\hline Peter & $1 ; 9-3 ; 2$ & 30,256 & 1,746 \\
\hline Naomi & $1 ; 8-3 ; 5$ & 14,656 & 802 \\
\hline Total & $1 ; 8-5 ; 1$ & 160,643 & 11,978 \\
\hline
\end{tabular}


In the data, there were 4,532 utterances including an infinitival complement clause, which contains a complement-taking verb and an infinitive or a participle. Among them, 2,679 utterances contained want and an infinitival complement, or the contracted form wanna. Seven other complement-taking verbs are quite common: have (or hafta), got (or gotta), make, know, like, try and see. Young children tend to use them with bare infinitives. In the NP-V-VP construction they primarily use wanna, hafta, and gotta. In the NP-V-NP-VP construction, they simply omit the infinitival marker (e.g. (Do you) want me open it? (Adam 2;9)). An average of $77.8 \%$ of the children's nonfinite complements are bare infinitives.

In this section, let us focus on the development of want-constructions. Want is generally the first and most frequent complement-taking verb in the data. Overall there are 2,682 utterances containing want and an infinitive. The majority of these utterances are of the NP-want-NP construction type (2,217 utterances), and 465 utterances are of the NP-want-NPVP type.

The earliest and most frequent is wanna and the mean age of its appearance is $2 ; 1$. It occurs in a highly formulaic matrix clause consisting of the first person pronoun $I$ and the verb. The early want-constructions are of the type NP-want-NP (e.g. I wanna bag. (Sarah 2;3), I want my dolly. (Sarah 2;4)). Soon after that, the NP-want-INF construction appears (e.g. I wanna ride my horse. (Sarah 2;4)). Both consist of a formulaic matrix clause (i.e. I wanna, I want, or I wan) and an open slot that is filled by a nominal expression or an infinitive. A few months later, new constructions in (1)-(4) emerge:

(1) I want a bandaid on. (Nina 2;4)

(2) I want ice cream in the refrigerator. (Sarah 2;10)

(3) I want it big. (Adam 4;9)

(4) I don't want it dat color. (Adam 4;9)

Diessel (p. 70) argues that these NP-want-NP-XP constructions help children bridge the gap between the early use of want in NP-want-NP and the later use of want in NP-want-NP-INF.

The NP-want-NP-INF construction, according to Diessel, also contains the same formulaic matrix clause. Adam first used want-NP-INF only in questions $(2 ; 9-3 ; 1)$ as in $(5)$ :

(5) a. Want me open it? $(2 ; 9)$

b. Want car go, go dat way? $(2 ; 10)$

c. Want me see it? $(2 ; 10)$

d. Do you want me get in? $(2 ; 10)$ 
e. Do you want he walk? $(2 ; 10)$

f. Do want wheel come off? $(2 ; 10) \quad$ (Diessel (2004: 70)) The exclusive use of the NP-want-NP-INF construction in (do-you)-want questions suggests that Adam learned this expression as a prefabricated chunk of a lexically specific utterance frame.

Furthermore, the NP-want-NP-INF construction contains a number of errors with the postverbal elements. There are utterances in which the postverbal NP occurs in nominative case as shown in $(6 a-d)$ and utterances in which the infinitive is replaced by a finite verb form as shown in $(6 e, f)$ :

(6) a. Do you want he walk like dis? (Adam 2;11)

b. You want... I finish my milk? (Adam 3;0)

c. You want I do a cartwheel? (Sarah 3;11)

d. I want she visit for a while. (Peter 2;10)

e. I want my doll's waking up. (Nina 2;5)

f. I want dat came out. (Sarah $2 ; 10$ )

(Diessel (2004: 71))

Based on these utterances, Diessel (p. 71) claims that the children interpret the NP-want-NP-INF construction as a combination of I want (or (do) you want) and a sentential argument realized as a finite complement clause.

To summarize the development of want-constructions, Diessel (pp. 68-72) argues that want occurs in four constructions that children learn in an incremental fashion. Figure 2 summarizes the development:

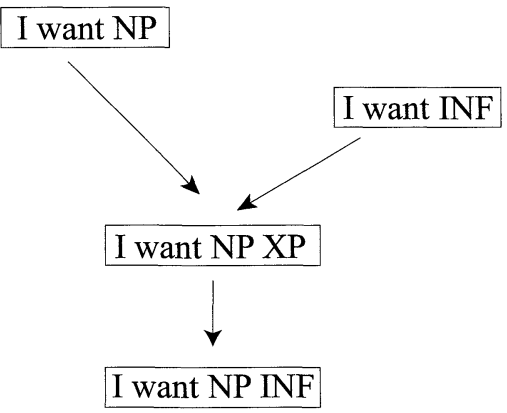

Figure 2. The development of want-constructions (Diessel (2004: 72))

Diessel (pp. 59-66) shows that the development of the constructions defined by other complement-taking verbs such as know and see is also incremental. He argues (pp. 73-76) that this kind of incremental development is crucially determined by the complexity of the emerging construction as well as the frequency of verbs in the input data, which is the speech children are exposed to daily. Based on the mean proportions of various 
complement-taking verbs in the mothers' NP-V-VP constructions, ${ }^{1}$ the mean age of verbs' appearance in the children's data and the correlation between the two sets of data, Diessel suggests that the order of the development is crucially determined by token frequency in the input data. The earliest infinitival complement constructions occur with complement-taking verbs that are frequent in the input.

\subsection{A Parametric Account}

Although the combination of the construction grammar and the usagebased model may explain the incremental development of infinitival constructions, there is a different attempt to explain the development of infinitival constructions based on the theory of generative grammar. Goro (2004) analyses the utterances of Adam (2;3-3;2), Sarah (2;3-3;2) (Brown (1973)) and Abe $(2 ; 4-3 ; 2)$ (Kuczaj (1976)) from the CHILDES database (MacWhinney (1995)). The children's utterances including want/need/like and their past forms were extracted using KWAL commands. Goro has shown that the omission rate of the infinitive to is much higher when the complements are with an overt subject (e.g. NP-V-NP-INF) than the omission rate in the empty subject complements (e.g. NP-V-INF). Examples are shown below:

(7) a. $\mathrm{D}(\mathrm{o})$ you wan $(\mathrm{t})$ me look both ways?

b. I don't want to look both ways. (Adam 3;0)

(8) I want it be cold. (Abe 2;10)

(Goro (2004: 206)) The development of infinitival complements of Adam and Abe are shown in the tables below:

Table 2: Adam's Development of Infinitival Complements (Goro (2004: 205))

\begin{tabular}{|l|c|c|c|c|}
\hline & $\begin{array}{c}\text { Empty subject } \\
\text { Complements }\end{array}$ & To-omissions & $\begin{array}{c}\text { Overt subject } \\
\text { complement }\end{array}$ & To-omissions \\
\hline $2 ; 3-2 ; 6$ & 24 & $2(8.3 \%)$ & 0 & 0 \\
\hline $2 ; 6-2 ; 10$ & 59 & $47(79.9 \%)$ & 7 & $6(85.7 \%)$ \\
\hline $2 ; 11-3 ; 2$ & 154 & $32(20.4 \%)$ & 192 & $190(99.0 \%)$ \\
\hline $3 ; 3-3 ; 6$ & 71 & $1(1.4 \%)$ & 35 & $3(8.8 \%)$ \\
\hline
\end{tabular}

1 Diessel notes (pp. 75-76) that the correlation between the input frequency and the age of appearance is much weaker in the case of NP-V-NP-VP constructions. Diessel suggests that the late appearance of some constructions with weak correlation can be explained in terms of the complexity of the emerging constructions. 
Table 3: Abe's Development of Infinitival Complements

(Goro (2004: 205))

\begin{tabular}{|l|c|c|c|c|}
\hline & $\begin{array}{c}\text { Empty subject } \\
\text { Complements }\end{array}$ & To-omissions & $\begin{array}{c}\text { Overt subject } \\
\text { complement }\end{array}$ & To-omissions \\
\hline $2 ; 3-2 ; 6$ & 6 & 0 & 1 & $1(100 \%)$ \\
\hline $2 ; 6-2 ; 10$ & 52 & $5(9.6 \%)$ & 22 & $17(77.3 \%)$ \\
\hline $2 ; 11-3 ; 2$ & 114 & $2(1.8 \%)$ & 14 & $1(7.1 \%)$ \\
\hline $3 ; 3-3 ; 6$ & 103 & 0 & 15 & 0 \\
\hline
\end{tabular}

Table 2 and 3 show that both Adam and Abe omit to more frequently in the overt subject complements than in the empty subject complements in the earlier stages of development. The gray areas show the asymmetry of to-omission. Until approximately the age of 3, children almost consistently avoid using to-infinitives in the overt subject complement, but there are optional to-omissions in the empty subject complements.

Based on the theory of generative grammar, Goro proposes a parametersetting account. Since nouns need to be case-marked and [-tense] $\mathrm{I}^{0}$ does not assign nominative case to the subject (Chomsky (1981)), overt subjects in to-infinitival complements must be case-marked by something other than $I^{0}$. Goro assumes that the overt subject within a complement IP is assigned case from the matrix verb through the process called exceptional case marking $(\mathrm{ECM})$ in adult grammar. The verb of the matrix clause assigns case to a non-local NP, as shown in (9):

(9) Bill believes [IP John to have lied]

$$
\text { case-marking }
$$

(Goro (2004: 207))

ECM in (9) is not allowed universally, since the counterpart of (9) in French is not grammatical, as shown in (10). This does not mean, however, that French lacks ECM entirely. When the complement is a small clause, its subject of the small clause successfully receives case from the matrix verb, as shown in (11). ECM in a small clause is also possible in English as in (12).

(10) *Bill croit [IP Jean avoir menti] Bill believes Jean to have lied

'Bill believes Jean to have lied.'

$\begin{array}{llll}\text { (11) Je crois [sc } & \text { Jean } & \text { intelligent] } \\ \text { I } & \text { consider } & \text { John } & \text { intelligent }\end{array}$

'I consider John intelligent.' 
(12) I consider [sC John intelligent]

(Goro (2004: 207)) Although ECM into a non-local NP and a small clause are both allowed in English, only ECM in a small clause is allowed in French. Based on these facts, Goro (2004: 207-208) argues that the outputs of French grammar and English grammar conform to a subset-superset relation, and that the parameter value which derives French-type ECM grammar must be the default value. This argument opens up the possibility that children acquiring English initially have a French-type ECM grammar. In order to license the case of overt complement subject, English children need a small clause structure, instead of a full IP projection. This means that the infinitival complement clauses in early child English are small clauses without an IPlayer (e.g. bare infinitives in the NP-V-NP-INF constructions). ${ }^{2}$

The asymmetry of to-omission in the NP-V-INF and the NP-V-NP-INF constructions which Goro found is probably the intermediate stage in the development of the want-constructions which Diessel revealed, that is, the stage between the development of the NP-V-INF constructions and the NP-V-NP-INF constructions. Therefore, the developmental stages of the want-constructions which Diessel analysed can also be explained by the parameter-setting account in generative grammar. These possibilities show that Diessel's approach based on construction grammar and the usage-based model is not the only way to explain children's incremental development of infinitival constructions.

\subsection{Wanna-Contraction}

An experimental study by Crain and Thornton (1998), which examined the wanna-contraction in wh-questions experimentally, may contradict Diessel's proposal that $I$ wanna and $I$ want are formulaic in early NP-want-INF and NP-want-NP-INF constructions. Let us consider wanna-contraction in an object extraction question and a subject extraction question below:

(13) Object extraction
a. Who do you want to meet $t$ ?
b. Who do you wanna meet $t$ ?

2 As we have seen, Diessel (p. 71) found several utterances in which the postverbal NP occurs with nominative case (see (6); e.g. You want I do a cartwheel? (Sarah 3;11), I want she visit for a while. (Peter 2;10)) These utterances might be a problem for Goro's analysis if he assumes that the subject of the small clause is assigned accusative case from the matrix verb want. 
(14) Subject extraction

a. Who do you want $t$ to meet Bill?

b. *Who do you wanna meet Bill?

In object extraction questions like (13), wanna-contraction is permitted, but in subject extraction questions like (14), it is not. The theory of generative grammar explains them as follows. In (13), the wh-phrase who is moved from object position, and a trace $t$ is left behind. The trace in object position does not interfere with the contraction of want to to wanna. In (14), the wh-phrase is moved from subject position of the lower clause (e.g. You want who to meet Bill?) and a trace is left between want and to. When the trace is between want and to, it interferes with the contraction of want to to wanna.

Since Diessel claims that wanna is used in a highly formulaic way in the beginning, his approach may predict that it is difficult for children at the early stage of language acquisition to distinguish the possibility of wanna contraction in object extraction questions and subject extraction questions like (13) and (14). Diessel has shown that the mean proportion of wanna in the mothers' NP-V-VP constructions is $43.0 \%$, which is the highest among the complement-taking verbs. The mean age of appearance of wanna in children's data is $2 ; 1$, which is the earliest among the children's constructions. The mean proportion of wanna in the mothers' NP-V-NP-VP constructions is $50.0 \%$, which is also the highest among the complementtaking verbs. The mean age of the appearance of want in children's NPV-NP-VP constructions is 2;7, which is the second earliest after that of the verb see. Since the frequency of subject and object extraction questions with want to in the mothers' and children's data has not been shown in Diessel, it remains unclear how the occurrence of subject and object extraction questions with want to in the mothers' data affects the children's wan$n a$-contraction in wh-questions. However, Diessel's approach may predict that children around $2 ; 1-2 ; 7$ have difficulty in distinguishing the possibility of wanna-contraction in object extraction questions and subject extraction questions if wanna is used in a highly formulaic way.

Although the exact comparison of children's behavior and their ages is not possible, the results of Crain and Thornton's (1998) experiment shows that children have early knowledge of wanna-contraction and its constraint, which seem to be difficult to explain by Diessel's analysis. Crain and Thornton tested 26 children between the ages of 2;10 and 5;5. Their protocols for eliciting object and subject extraction questions are shown below: 
(15) Object extraction questions

Experimenter: The rat looks kind of hungry. I bet he wants to eat something. Ask him what.

Child: What do you wanna eat?

Ratty: Is that pepperoni pizza over there? I'll have some of that.

(16) Subject extraction questions ${ }^{3}$

(Crain and Thornton (1998: 181))

Experimenter: I bet the rat wants someone to brush his teeth for him. Ask him who.

Child: Who do you want to brush your teeth?

(*Who do you wanna brush your teeth?)

Ratty: You!

(Crain and Thornton (1998: 182))

Among the 26 children they tested, the overall results of 14 children $(3 ; 6-5 ; 5)$ were given, since those children produced two or more questions of each type. They exhibited a strong preference for contraction in the object extraction questions. Of the 68 questions elicited, $60(88 \%)$ showed contraction. The 14 children produced a total of 74 subject extraction questions. Of these, $68(92 \%)$ had no contraction. Crain and Thornton (1998: 182-185) argue that, although some presence of contractions in subject extraction questions cannot be easily explained by the theory of generative grammar, it is true that no child shows contractions in subject extraction questions as often as in object extraction questions.

The individual results of younger children should be focused to compare with Diessel's analysis. The results of the children from $2 ; 10$ to $3 ; 7$ are shown in the table below:

${ }^{3}$ For the critical subject extraction questions, a more complex protocol was prepared to encourage the child to ask a full question. The idea was that if several potential events could take place, the child would realize that a full question was needed to distinguish among them and that the question fragment "Who do you want?" would not be felicitous. The protocol is as follows (Crain and Thornton (1998: 182)):

(i) Experimenter: In this game, there's a baby, a dog, and Cookie Monster, OK? And some different things are going to happen, and the rat gets to choose who gets to do those different things. Now, one of these guys gets to take a walk, one of these guys gets to take a nap, and one of these guys gets to eat a cookie. Let's do the cookie first. So, one of these guys gets to eat a cookie, right? Ask the rat who he wants.

Child: Who do you want to eat a cookie?

Ratty: Cookie Monster! 
Table 4: Data of the 5 youngest children in Crain and Thornton (1998: $183,184)$

\begin{tabular}{|c|c|c|c|c|c|c|}
\hline & \multicolumn{3}{|c|}{ Object } & \multicolumn{3}{c|}{ Subject } \\
\hline Subj/Age & Want to & Wanna & Other & Want to & Wanna & Other \\
\hline CA 3;7 & 1 & 5 & - & 7 & - & - \\
\hline MC 3;7 & - & 3 & - & - & - & - \\
\hline JE 3;6 & - & 3 & - & 5 & - & - \\
\hline MA 3;3 & 1 & 1 & - & - & - & - \\
\hline PI 2;10 & - & 1 & - & - & - & - \\
\hline
\end{tabular}

Although there are not many instances of wanna/want to in Table 4 and the ages of the children are higher than those in Diessel's study, it shows that no young child produced wanna in subject extraction questions. Crain and Thornton (1998: 177-185) argue that the productions of wanna in both object and subject extraction questions are expected if the acquisition of wanna-contraction is affected by the frequency in the input data. Until children learn from the input data that wanna-contraction is prohibited in subject extraction questions, they should produce wanna in both object and subject extraction questions. However, the results of Crain and Thornton show that children seem to have acquired the use of wanna-contraction and its constraint from early on, and thus the acquisition of wanna-contraction and its constraint are better explained by the innateness hypothesis than by the usage-based model on which Diessel is based.

To summarize this section, Diessel proposes that the development of infinitival constructions proceeds in an incremental fashion, based on the frequency of the various complement-taking verbs in the input data and the complexity of the emerging constructions. However, we have seen that the incremental development can be explained by a parametric approach (Goro (2004)). We have also pointed out that the early acquisition of wannacontraction and its constraint (Crain and Thornton (1998)) may not be well explained by the usage-based model which Diessel adopted.

\section{Relative Clauses}

\subsection{Diessel's Analysis}

Like infinitival complement constructions, Diessel (pp. 116, 129-148) argues that complex sentences including relative clauses develop via clause expansion. The earliest relative clauses occur in presentational construc- 
tions that consist of a copular clause and a relative clause including an intransitive verb. Although these constructions are bi-clausal, they contain only a single proposition. The clauses are called PN (predicate nominal)relatives, which are shown below:

(17) a. This is the sugar that goes in there. (Nina 3;0)

b. Here's a tiger that's gonna scare him. (Nina 3;1)

c. It's something that you eat. (Adam 4;0)

d. What is that he has around his back? (Adam 3;8)

(Diessel (2004: 131))

According to Diessel (p. 132), apart from PN-relatives (48.5\%), relatives with isolated nouns ('People dat can jump in dere.' (Adam 4;0)) and object relatives ('You left this toy I am playing with.' (Peter 3;1)) are quite common: the mean proportions of those relatives are $23.8 \%$ and $21.5 \%{ }^{4}$ On the other hand, oblique relatives ('What happened to the thing that I went to?' (Adam 4;3)) and subject relatives (SUBJ-relatives; 'The person who puts dem on has to.' (Adam 3;11)) are very rare: the mean proportions of those relatives are $5.6 \%$ and $0.7 \%$.

According to Diessel (pp. 131-136), in children's data, SUBJ-, OBJ-, and OBL-relatives occur in sentences containing two propositions expressed in two full-fledged clauses, but PN- and N-relatives include only a single proposition. Following Lambrecht (1988), Diessel (p. 132) assumes that the copular clauses of PN-relatives are 'propositionally empty.' They do not denote an independent state of affairs, but they function to establish a referent in focus position, making it available for the predication expressed in the relative clause.

In some of children's PN-relatives, as shown in (18), the verb phrase, following a copular clause, can be analyzed as a relative clause without a relativizer, which is ungrammatical in standard English. ${ }^{5}$

${ }^{4}$ According to Diessel (p. 60), mean proportions are calculated by summing the scores (i.e. percentages) from each child and then dividing the sum by the number of children. Diessel (p. 60) notes that mean proportions are more representative than percentages because they factor out the differences in corpus size between the corpora of individual children.

5 Adopted from Lambrecht (1988: 319), Diessel (pp. 134-135) shows that these relative clauses without relativizers do occur in certain nonstandard varieties of adult speech:

(i) There's something keeps upsetting him.

(ii) There's a lot of people don't know that. 
(18) a. That's doggy turn around. (Nina 1;11)

b. This is my doggy cries. (Nina 2;0)

c. Here's a mouse go sleep. (Nina 2;3)

d. What's this go in there? (Peter 2;0)

e. There's a tape go around right there. (Peter 2;0)

f. It's the wheels go. (Peter 2;3)

g. There's somebody's gonna crash on him. (Peter 2;9)

h. What is dis came out (Adam 3;1)

i. And that's the birdie scream. (Sarah $4 ; 3$ )

(Diessel (2004: 134))

Diessel (pp. 134-135) argues that these truncated relative clauses serves as a precursor to the presentational relative construction: three of the four children, Peter, Nina and Sarah, used these truncated relative clauses several months before they used other relative clauses, while Adam began to use them together with presentational relatives with a relativizer.

As the children grow older (after the age of 3), the relative constructions become increasingly more complex and diverse. While almost all of the earliest relative clauses occur in presentational constructions including a short and formulaic copular clause, the older children produce the relatives frequently attached to a noun or NP in an ordinary matrix clause. The older children's relatives contain two propositions.

Diessel (pp. 144-148) discusses five factors for explaining early and frequent use of presentational relative constructions. Firstly, the earliest relative clauses are built on lexically specific constructions (i.e. presentational relatives containing a pronominal subject, $b e$, and a predicate nominal), which are deeply entrenched at the time children begin to use relative clauses. Secondly, presentational relatives are commonly used to focus the hearer's attention on elements in the surrounding situation, because they are pragmatically useful in parent-child speech. Thirdly, since the information structure of the presentational relatives is very similar to the information structure of simple sentences, it should be easy for children to learn them. Fourthly, adults make frequent use of PN-relatives in child-directed speech, and thus the input frequency has an effect on the development. Finally, the children's early relatives express a single proposition, while the complex sentences including two propositions emerge later. The complexity has an effect in addition to the input frequency.

\subsection{Truncated Presentational Relatives}

Another construction in children's production has a similar property to the 
children's truncated presentational relatives that Diessel reports. Yamakoshi (1999a, 2002a, 2002b) reports that children acquiring different languages often do not pronounce $w h$-phrases in wh-questions (henceforth ' $w h$-drop questions'), which is ungrammatical in adult speech. The blank spaces in (19) show that overt $w h$-phrases should appear in adult $w h$-questions:

a. $\square$ my shoes gone?

'(Where) (have) my shoes gone?'

(English; Jenny 1;10 from Radford (1990))

b. $\square$ heb Sarah nou pakt? have Sarah then take '(What) did Sarah take?'

(Dutch; Laura 3;5.13 from Van Kampen (1997))

c. $\square$ är de andra bilen? is the other car '(Where) is the other car?'

(Swedish; Tor 2;9 from Santelmann (1997))

d.

$\square$ kommt der Pappi denn?
come the Papa then

'(When) does Daddy come?' (German; from Felix (1980))

Based on the theory of generative grammar, Yamakoshi (1999a, 2002a, 2002 b) proposes that, in children's $w h$-drop questions, a phonologically null wh-operator which corresponds to an overt wh-operator in adult speech is used in children's wh-drop questions. ${ }^{6}$ The null wh-operator is moved to the CP specifier position, as with the overt wh-movement:

(20) The structure of children's wh-drop question

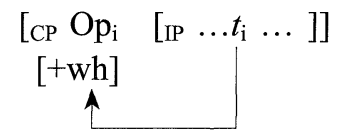

(Yamakoshi (1999a: 727))

Along the lines of wh-question formation, it is natural to assume that the movement of a relative pronoun is involved in a relative clause in adult grammar as shown below:

(21) I know [NP the man [ ${ }_{\mathrm{CP}}$ whom [ IP Mary will invite $\left.\left.\left.t\right]\right]\right]$.

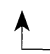

From (20) and (21), it is also possible to say that children's truncated relative clauses in (22) involves a phonologically null relative pronoun, as

${ }^{6}$ Yamakoshi (1999b) suggests that the dropping of wh-phrases is due to a pragmatic principle called the principle of least effort (Haiman (1983), Newmeyer (1998)). 
shown below:

(22) That's [NP doggy [CP Op [IP $t$ turn around]]]. (Nina 1;11) $(=(18 \mathrm{a}))$ Therefore, children's truncated relative clauses can be explained by assuming the presence of a null operator within the theory of generative grammar. This shows that Diessel's analysis of the truncated relative clauses as a precursor to the presentational relative clauses is not the only way to explain children's truncation of relative pronouns.

\subsection{Early Comprehension of Relative Clauses}

By conducting an experiment, Isobe (2003) has shown that knowledge of head-internal relative clauses emerges very early in the acquisition of Japanese, in spite of the infrequency in the adult input. Isobe's results seem to pose a problem for Diessel's analysis of relative clauses.

Japanese allows two kinds of relative clauses: head-external relative clauses (HERCs) and head-internal relative clauses (HIRCs), as shown below:

(23) Head-external relative clause

John-wa [[ Mary-ga teeburu-no ue-ni $t_{\mathrm{i}}$ oitekureta]

John-Top Mary-Nom table-Gen top-Loc put-Past ringo $\mathrm{i}_{\mathrm{i}}$ ]-o tabe-ta.

apple-Acc eat-Past

'John ate the apple which Mary put on the table.'

(24) Head-internal relative clause

John-wa [[ Mary-ga teeburu-no ue-ni ringo-o

John-Top Mary-Nom table-Gen top-Loc apple-Acc

oitekureta] no]-o tabe-ta.

put-Past Comp-Acc eat-Past

'John ate the apple which Mary put on the table.'

(Isobe (2003: 359))

In a HIRC, the nominal head appears in a position internal to the modifying clause.

Following Cole (1987), Isobe (2003) takes a parameter-setting approach. HIRCs are possible only in languages which have the following properties: (i) the word order is Object-Verb (i.e. the head parameter) and (ii) null pronouns are used productively (the pro-drop parameter). To derive this correlation, Cole assumes the structure in (25), which is also assumed in Isobe (2003) for Japanese HIRCs (Also see Hoshi (1995), Ito (1986), Watanabe (1992)): 


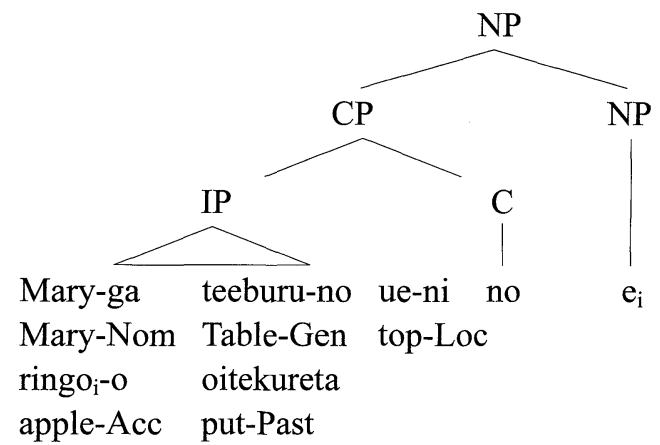

(Isobe (2003: 360))

Cole (1987) argues that the possibility of HIRCs is determined by the setting of the word order parameter and the pro-drop parameter. It has been shown that these parameters are set very early in Japanese, before the age of 2 (Clancy (1985), Miyahara (1973), Nakayama (1996)). Based on the early acquisition of these parameters, Isobe predicts that knowledge of HIRC should emerge very early. To confirm the prediction, Isobe tested 16 Japanese-speaking children from the ages of $3 ; 0$ to $4 ; 6$. In the experiment, the children were tested individually and asked to answer a question like (26). The test question is structurally ambiguous between HIRC in (26a) and HERC in (26b).

(26) Kumasan-ga naiteiru-no-o dooyatte waraw-ase-ta-kana?

a. HIRC structure:

pro [Kumasan-ga naiteiru no]-o dooyatte the bear-Nom was crying Comp-Acc how waraw-ase-ta-kana?

laugh-make-Past-Q

'How did he make laugh the bear that was crying?'

b. HERC structure:

Kumasan-ga [naiteiru no]-o dooyatte

the bear-Nom was crying one-Acc how waraw-ase-ta-kana?

laugh-make-Past-Q

'How did the bear make laugh the one that was crying?'

(Isobe (2003: 362))

In (26a), pro refers to an individual salient in the discourse and the underlined part is a HIRC. In (26b), kumasan-ga (the bear-Nom) is the matrix subject. The morpheme no in the underlined part is a pronoun translated as 
'the one,' which is the head of the HERC.?

In the experiment, the children were told a story accompanied by an animation presented on a laptop computer. The character Meowce appeared on the screen and asked the children a question like (26). An example, translated from Japanese to English, is shown below:

(27) Pikachu, a dinosaur and a bear are watching TV in a room. Suddenly, a monster appeared on the screen. Looking at the monster, the dinosaur started laughing, but the bear was very scared and began to cry. In order to console the bear, Pikachu made a face at the bear. The bear stopped crying and smiled at Pikachu because his face was so funny. After watching TV, they all got hungry. The dinosaur found some apples that were on the table, but there were only two of them. The dinosaur and the bear took an apple, and there was no apple for Pikachu. The dinosaur and the bear were smiling, but Pikachu began to cry. Since the bear felt very sorry for Pikachu, he gave Pikachu his candy. Pikachu felt very happy to have a piece of candy.

Meowce: (structurally ambiguous)

Kumasan-ga naiteiru-no-o dooyatte

the bear-Nom was crying-Comp/one-Acc how

waraw-ase-ta-kana?

laugh-make-Past-Q

(a) 'How did he make laugh the bear that was crying?' (HIRC interpretation; The answer is "By making a face.")

(b) 'How did the bear make laugh the one that was crying?' (HERC interpretation; The answer is "By giving his candy to Pikachu.")

(Isobe (2003: 363-364))

The overall results are as follows: the children gave the HIRC interpretation to the structurally-ambiguous questions $96.9 \%$ of the time $(62 / 64)$. They provided the HERC interpretation only $3.1 \%$ of the time $(2 / 64)$. Regarding the unambiguous questions, they gave the correct HERC

7 In addition to (26), structurally-unambiguous sentences like (i) were used to check whether the children are able to comprehend the HERC structure. Only the HERC interpretation is possible for (i):

(i) Kumasan-ga dooyatte [naiteiru no]-o waraw-ase-ta-kana? the bear-Nom how was crying one-Acc laugh-make-Past-Q

'How did the bear make laugh the one that was crying?' (Isobe (2003: 363)) 
interpretation $87.5 \%$ of the time (See footnote 7 ). These results show that the Japanese-speaking three-year-olds already have knowledge of the HIRC.

What is crucial in Isobe (2003) is that, in addition to the experiment, the frequency of HIRCs is examined in the parental input of two Japanese children (Aki and Tai; Miyata $(1995,2000)$ ) in the CHILDES database (MacWhinney (1995)). Isobe found that HIRCs are extremely infrequent in the parental input: only two potential examples were found in more than 124,000 lines of adult speech, as shown below:

(28) HIRCs in the parental input (Isobe (2003: 365))

$\begin{array}{lcc} & \text { \# utterances } & \text { \# Potential HIRCs } \\ \text { Aki (56 files) } & 21,056 & 0 \\ \text { Tai (75 files) } & 103,304 & 2\end{array}$

To summarize, the experimental results we have seen above show that Japanese-speaking children acquire HIRCs in spite of the infrequency of HIRCs in the parental input. These results favor the innate hypothesis in generative grammar. Innate linguistic knowledge must include some knowledge of HIRCs, and thus HIRCs are acquired quite early despite the infrequency in the parental input. Although HIRCs are different from HERCs which Diessel examined, the results of Isobe (2003) seem to contradict with Diessel's usage-based approach, as the frequency of the target constructions in the input data is one of the essential factors in Diessel's approach for the acquisition of relative clauses and other complex sentences.

\section{Discussion}

By examining the development of the four types of children's complex sentences in detail, Diessel (pp. 174-185) argues that, in general, children's early complex sentences are organized around concrete lexical expressions. More abstract representations of complex sentences emerge later, when children have acquired enough lexically specific constructions to generalize across them. Children eventually learn a network of interrelated constructions at different levels of highly abstract schemas. The constructions are related to each other by specific links. The network of finite complement clause constructions which Diessel proposes is given below as an example. 


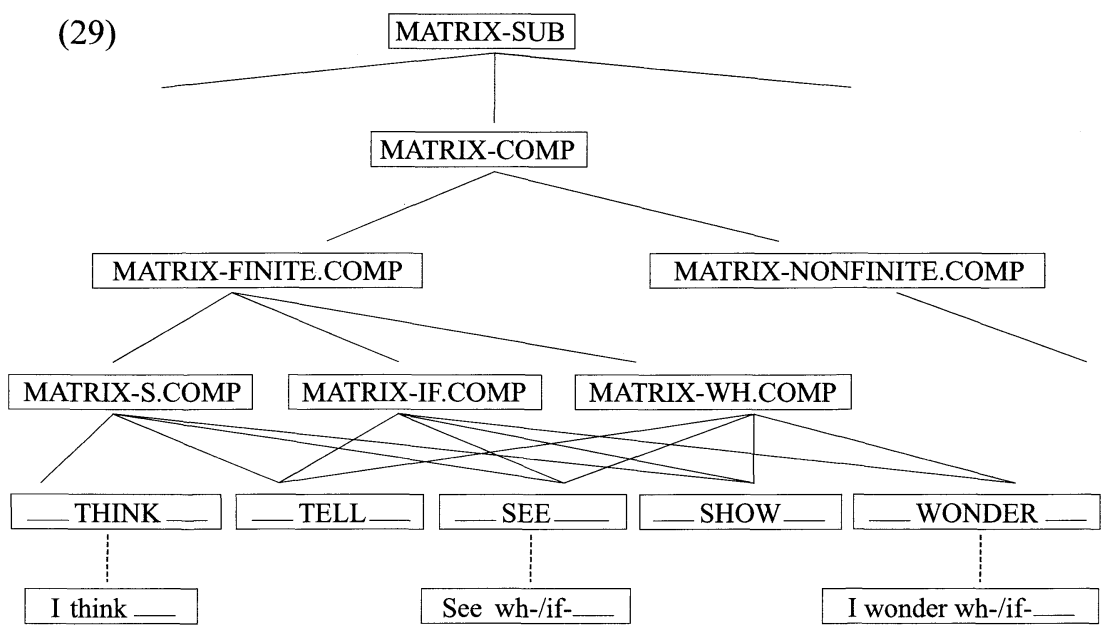

Figure 3. Network of finite complement clause constructions.

(Diessel (2004: 182))

The vertical dimension of the network indicates the degree of abstractness or schematicity: constructions near the top of the network are more schematic than constructions at the lower levels. The lowest level of the network shows constructions that include concrete lexical items. These items represent formulaic matrix clauses, stored as prefabricated chunks, which combine with specific types of complement clauses. At the second lowest level, the matrix clauses are lexically specific; they are organized around individual complement-taking verbs, but in contrast to the formulaic matrix verbs the lexically specific constructions are instantiations of more schematic constructions including abstract grammatical categories.

Although Diessel's explanation using networks seems to be natural, there are several inadequacies. Firstly, according to Diessel, the emergence of a constructional schema presupposes a significant number of types, and thus the constructional schemas in the upper part of the network emerge later when children have learned a greater variety of complement-taking verbs. However, according to Diessel's data, what the children learned by the end of the time period are isolated constructions at the bottom of the network. Most of these constructions are organized around formulaic matrix clauses. For Diessel's analysis to be borne out, it is necessary to show when and how the constructional schemas emerge, and how many occurrences of each type are needed for their emergence.

Secondly, we have shown that Diessel's approach is not the only way to 
explain children's development of complex sentences. We have seen that a parameter-setting account based on the innateness hypothesis (Goro (2004)) captures the omission of to-infinitives in the course of acquisition of infinitival complement constructions. We have also shown that the truncated relative clauses, namely relative clauses without relative pronouns, can be explained by assuming the presence of phonologically null operators, following the analyses of children's $w h$-drop questions in Yamakoshi (1999a, 2002a, 2002b). To argue against the innateness hypothesis, Diessel must show that his analyses based on construction grammar and the usage-based model are able to explain the acquisition of complex sentences better than the analyses based on the innateness hypothesis.

Finally, we have pointed out that Diessel's analyses cannot explain the results of certain experimental studies based on the theory of generative grammar. As we have seen, Crain and Thornton (1998) have shown that children have knowledge of wanna-contraction and its constraint from early on, by testing children's production of wanna in subject and object extraction questions. Since Diessel claims that I wanna is used as a highly formulaic phrase at the earliest stage of the acquisition of the want-construction, Diessel's analysis does not seem to explain how children distinguish the possibility of wanna-contraction in subject and object extraction questions. Furthermore, according to Diessel's approach, the frequent occurrences of certain constructions in the input data are indispensable for children to acquire them. However, Isobe (2003) has shown that the acquisition of head-internal relative clauses (HIRCs) in Japanese is acquired quite early in spite of the infrequency of those relative clauses in the adult input. The results of Isobe's experiment contradict with Diessel's analysis with respect to the early acquisition of HIRCs despite its infrequency in the input data.

Of course the innateness hypothesis is not without problems in explaining children's language acquisition. Since generative grammar assumes that the innate linguistic knowledge is genetic endowment, it is necessary to explain why some complex constructions are not available to children from early on and why children sometimes make mistakes which adults do not. Although several attempts have been made, such as the maturation hypothesis (Bore and Wexler (1987, 1992)), the weak continuity hypothesis (Weissenborn, Goodluck and Roeper (1992)) and processing deficits (Grodzinsky and Reinhart (1993)), we do not yet have a conclusive explanation for how children's language acquisition proceeds.

To summarize, both Diessel's approach and the innateness hypothesis still 
have unsolved issues to work out. Further investigation into children's knowledge of language and their language acquisition process will eventually enable us to choose between the usage-based model and the innateness hypothesis in the future.

\section{Conclusion}

Diessel (2004) has analyzed the acquisition of complex sentences based on construction grammar and the usage-based model, and has argued against the innateness hypothesis proposed in the theory of generative grammar. We have shown that Diessel's argument is not sufficient to refute the innateness hypothesis for the following reasons. First, Diessel's observations such as children's omission of to-infinitives and truncated relative clauses can be accounted for equally well by other analyses based on the theory of generative grammar such as parameter setting and the postulation of null operators. Second, there are certain experimental results which presumably run afoul of Diessel's approach such as the early acquisition of the constraint regarding wanna-contraction and the early acquisition of headinternal relative clauses in Japanese despite their infrequency in the parental input.

\section{REFERENCES}

Barlow, Michael and Susanne Kemmer (2000) Usage-based Models of Language, CSLI, Stanford.

Bloom, Lois P. (1973) One Word at a Time: The Use of Single Word Utterance before Syntax, Mouton, The Hague.

Borer, Hagit and Kenneth Wexler (1987) "The Maturation of Syntax," Parameter Setting, ed. by Tom Roeper and Edwin Williams, 123-172, Reidel, Dordrecht.

Borer, Hagit and Kenneth Wexler (1992) "Bi-unique Relations and the Maturation of Grammatical Principles," Natural Language and Linguistic Theory 10, 147-189. Brown, Roger (1973) A First Language, Harvard University Press, Cambridge, MA. Bybee, Joan (1985) Morphology, John Benjamins, Amsterdam.

Bybee, Joan (1995) "Regular Morphology and the Lexicon," Language and Cognitive Processes 10, 425-455.

Bybee, Joan (2001) Phonology and Language Use, Cambridge University Press, Cambridge.

Chomsky, Noam (1965) Aspects of the Theory of Syntax, MIT Press, Cambridge, MA.

Chomsky, Noam (1981) Lectures on Government and Binding, Foris, Dordrecht. 
Chomsky, Noam (1986) Knowledge of Language: Its Nature, Origin and Use, Praeger, New York.

Chomsky, Noam (1995) The Minimalist Program, MIT Press, Cambridge, MA.

Chomsky, Noam (2000) "Minimalist Inquiries: The Framework," Step by Step: Essays in Minimalist Syntax in Honor of Howard Lasnik, ed. by Roger Martin, David Michaels and Jan Uriagereka, 89-155, MIT Press, Cambridge, MA.

Chomsky, Noam (2001) "Derivation by Phase," Kenneth Hale; A Life in Language, ed. by Michael Kenstowicz, 1-52, MIT Press, Cambridge, MA.

Chomsky, Noam (2004) "Beyond Explanatory Adequacy," Structures and Beyond: The Cartography of Syntactic Structures, Vol. 3, ed. by Adreian Belletti, 104131, Oxford University Press, Oxford.

Chomsky, Noam and Howard Lasnik (1993) "The Theory of Principles and Parameters," Syntax: An International Handbook of Contemporary Research, ed. by Joachim Jacobs, Arnim von Stechow, Wolfgang Sternefeld and Theo Vennemann, Walter de Gruyter, Berlin. [Reprinted in The Minimalist Program, Noam Chomsky, 1995, MIT Press, Cambridge, MA.]

Clancy, Patricia (1985) "The Acquisition of Japanese," The Crosslinguistic Study of Language Acquisition, Vol. 1: The Data, ed. by Dan I. Slobin, 373-524, Erlbaum, Hillsdale, NJ.

Cole, Peter (1987) "The Structure of Internally Headed Relative Clauses," Natural Language and Linguistic Theory 5, 277-302.

Crain, Steven and Rosalind Thornton (1998) Investigations in Universal Grammar: A Guide to Experiments on the Acquisition of Syntax and Semantics, MIT Press, Cambridge, MA.

Croft, William (2001) Radical Construction Grammar, Oxford University Press, Oxford.

Elman, Jeffrey L., Elizabeth A. Bates, Mark H. Johnson, Annette Karmiloff-Smith, Domencio Parisi and Kim Plunkett (1996) Rethinking Innateness: A Connectionist Perspective on Development, MIT Press, Cambridge, MA.

Felix, Sacha (1980) "Cognition and Language Development: A German Child's Acquisition of Question Words," Studies in Language Acquisition, ed. by Dietrich Nehls, 91-109, Gross, Heidelberg.

Fillmore, Charles J., Paul Kay and Catherine O'Connor (1988) "Regularity and Idiomaticity in Grammatical Constructions: The Case of let alone," Language 64, 501-538.

Fillmore Charles J. and Paul Kay (1993) Construction Grammar, University of California, Berkeley.

Goldberg, Adele E. (1995) A Construction Grammar Approach to Argument Structure, University of Chicago Press, Chicago.

Goro, Takuya (2004) "On the Distribution of To-infinitives in Early Child English," Proceedings of the 28th Annual Boston University Conference on Language Development, 199-210, Cascadilla Press, Somerville, MA.

Grodzinsky, Yosef and Tanya Reinhart (1993) "The Innateness of Binding and the Development of Coreference: A Reply to Grimshaw and Rosen," Linguistic In- 
quiry 24, 69-203.

Haiman, John (1983) "Iconic and Economic Motivation," Language 59, 781-814.

Hoshi, Koji (1995) Structural and Interpretive Aspects of Head-Internal Relative Clauses, Doctoral dissertation, University of Rochester.

Isobe, Miwa (2003) "Head-Internal Relative Clauses in Child Japanese," Proceedings of the 27th Annual Boston University Conference on Language Development, 358-369, Cascadilla Press, Sommerville, MA.

Ito, Junko (1986) "Head-Movement at LF and PF: The Syntax of Head-Internal Relatives in Japanese," University of Massachusetts Occasional Paper in Linguistics 11, 109-138.

Kampen, Jacqueline Van (1997) First Steps in Wh-movement, Eburon, Delft.

Kuczaj, Stan A. (1976) -ing, -s and -ed: A Study of the Acquisition of Certain Verb Inflections, Doctoral dissertation, University of Minnesota.

Langacker, Ronald W. (1987) Foundation of Cognitive Grammar, Vol. 1, Theoretical Prerequisites, Stanford University Press, Stanford.

Langacker, Ronald W. (1988) "A Usage-Based Model," Topics in Cognitive Linguistics, ed. by Brygida Rudzka-Ostyn, 127-161, John Benjamins, Amsterdam.

Langacker, Ronald W. (1991) Foundation of Cognitive Grammar, Vol. 2, Descriptive Application, Stanford University Press, Stanford.

Langacker, Ronald W. (2000) "A Dynamic Usage-Based Model," Usage-Based Models of Language, ed. by Michael Barlow and Susanne Kemmer, 1-63, CSLI Publications, Stanford.

Lambrecht, Knud (1988) "There Was a Farmer Had a Dog: Syntactic Amalgams Revisited," BLS 14, 319-339.

MacWhinney, Brian (1995) The CHILDES Project. Tools for Analysing Talk, 2nd ed., Erlbaum, Hillsdale, NJ.

Miyahara, Kazuko (1973) "Language Development in a Young Japanese ChildAcquisition of Particles," ms., Kyushu University.

Miyata, Susanne (1995) "The Aki Corpus: Longitudinal Speech Data of a Japanese Boy Aged 1;6 to 2;12," Bulletin of Shukutoku Junior College 39, 183-191.

Miyata, Susanne (2000) "The TAI Corpus: Longitudinal Speech Data of a Japanese Boy Aged 1;5.20-3;1.1," Bulletin of Shukutoku Junior College 34, 77-85.

Nakayama, Mineharu (1996) Acquisition of Japanese Empty Categories, Kurosio, Tokyo.

Newmeyer, Frederick J. (1998) Language Form and Language Function, MIT Press, Cambridge, MA.

Radford, Andrew (1990) Syntactic Theory and the Acquisition of English Syntax, Blackwell, Cambridge, MA.

Sachs, Jacqueline (1983) "Talking about There and Then: The Emergence of Displaced Reference in Parent-Child Discourse," Children's Language Vol. IV, ed. by Keith E. Nelson, 359-438, Erlbaum, Hillsdale, NJ.

Santelmann, Lynn (1997) "Wh-less Questions in Early Swedish: An Argument for Continuity in Language Development," Cornell Working Papers in Linguistics 15, 217-253, Cornell University, Ithaca, NY. 
Suppes, Patrick (1973) "The Semantics of Children's Language," American Psychologist 88, 103-114.

Watanabe, Akira (1992) "Wh-in-situ, Subjacency, and Chain Formation," MIT Occasional Papers in Linguistics 2, MIT, Cambridge, MA.

Weissenborn, Jürgen, Helen Goodluck and Tomas Roeper (1992) "Introduction: Old and New Problems in the Study of Language Acquisition," Theoretical Issues in Language Acquisition: Continuity and Change in Development, ed. by Jürgen Weissenborn, Helen Goodluck and Tomas Roeper, 1-23, Erlbaum, Hillsdale, NJ.

Yamakoshi, Kyoko (1999a) "The Acquisition of Wh-questions: Wh-drop in Child Swedish, Dutch, German, English, French, Spanish and Japanese," Proceedings of the 23rd Annual Boston University Conference on Language Development, 720-731, Cascadilla Press, Somerville, MA.

Yamakoshi, Kyoko (1999b) Least Effort in the Course of Language Acquisition: WHdrop in Child Speech, Doctoral dissertation, Ochanomizu University.

Yamakoshi, Kyoko (2002a) "Wh-drop in Child Languages and Adult American Sign Language," Proceedings of Console 9, 217-231, Leiden University.

Yamakoshi, Kyoko (2002b) "Null Wh and Null Subjects in Child Speech," Proceedings of Generative Approaches to Language Acquisition 2001, 283-288, Associação Portuguesa de Linguistica, Lisboa.

Senshu University

2-1-1 Higashi-mita, Tama-ku

Kawasaki, Kanagawa 223-0044

e-mail: yamakosi@isc.senshu-u.ac.jp 